\title{
TRANSFORMACIONES EN LOS INSTRUMENTOS DE CONTROL PARLAMENTARIO
}

\author{
ELVIRO ARANDA ÁLVAREZ \\ Profesor Titular de Derecho Constitucional \\ Universidad Carlos III
}

\author{
SUMARIO \\ I. Introducción. \\ II. La función de control político. \\ III. Preguntas parlamentarias en Pleno. \\ IV. Las interpelaciones parlamentarias. \\ V. Las Comisiones de Investigación. Funcio- \\ namiento y mejora que se desprende de \\ la práctica de los últimos años. \\ V. Las Proposiciones no de Ley. \\ VI. Información gubernamental: comunica- \\ ciones, programas y planes remitidos por \\ el Gobierno. \\ VII. Debate del Estado de la Nación. \\ VIII. Cuestión de Confianza y Moción de Cen- \\ sura. \\ IX. A modo de conclusión.
}

\section{INTRODUCCIÓN}

El Parlamento y las funciones que tiene atribuidas han generado desde siempre un fuerte debate entre politólogos y juristas. Es lógico que a sí sea, no debemos de olvidar que el Parlamento es una institución compleja con una gran carga simbólica que hace efectiva en la sociedad contemporánea la democracia representativa.

Precisamente esa condición de institución compleja y gran simbolismo, que desarrolla funciones que van más allá de las conferidas de manera explícita en la Constitución, hace que el estudio y análisis del Parlamento sea extrema- 
damente difícil. Es cierto, como ha señalado Enrique Guerrero, que el Parlamento es mucho más que un órgano o un poder. Se ha de ver en comunicación con la sociedad a la que representa e integrado en el aparato del Estado del que forma parte ${ }^{1}$. Por ello, la función representativa, que tan importante es y tan frecuentemente se olvida al hablar del Parlamento, se nos presenta como la forma de relacionar sustancialmente a la Institución con la sociedad. El pueblo es el soberano en democracia y la forma de articularse la democracia moderna es la representación. Luego la existencia de una institución capaz de expresar la voluntad general mediante la acción política de los sujetos que la conforman se convierte en la condición central del Parlamento que da "vida política" a los ciudadanos y asegura la legitimidad democrática de los órganos estatales ${ }^{2}$.

Pero el Parlamento también es un órgano del Estado y por ello está incardinado en su estructura y organizado por su Derecho.

La Constitución dice en su artículo 66 que Las Cortes Generales representan al pueblo español y están formadas por el Congreso de los Diputados y el Senado. De esta manera nuestro Parlamento, compuesto del Congreso y el Senado, se integra en el sistema de órganos constitucionales para perfeccionar, entre otras, la misión de representar al pueblo español. Es un Parlamento que, de acuerdo con el artículo 1.3 CE, participa en la organización de la forma de gobierno parlamentaria ${ }^{3}$. En nuestro caso se integra en un modelo que por mor de la posición que ocupa respecto de otros poderes se ha denominado parlamentarismo racionalizado. Esta circunstancia, la incardinación de la institución en el modelo de gobierno, es un elemento que va a condicionar el funcionamiento y la organización del Parlamento y que confunde el análisis que sobre él y sus funciones se hacen ${ }^{4}$.

1 GUERRERO SALOM, E. El Parlamento. Qué es, cómo funciona, qué hace. Editorial Síntesis, 2004. Pág. 28. También de este autor, "La actividad del Congreso: Una evaluación", El Congreso de los Diputados en España: funciones y rendimiento. MARTÍNEZ, A., (Ed.), Técnos 2000. págs. 141-172. SANTAMARIA, J., "El papel del parlamento durante la consolidación de la democracia y después". A Parlamento y consolidación democrática. JUAN CANO BUESO, J., PORRAS NADALES, A., (Coords.), Tecnos 1994. págs. 133-146.

2 La relación sociedad, opinión pública y parlamento ha sido extensamente debatida en nuestra doctrina, por todos vid, DE VEGA GARCÍA, P. "La Función legitimadora del Parlamento", Parlamento y opinión pública. PAU VALL, F., (Coord.), Asociación Española de Letrados de Parlamentos. Tecnos. 1995. "Democracia, representación y partidos políticos". MOLAS, I., Parlamento y Democracia. Edit. Fundación Pablo Iglesias. 1982. págs. 70-79. SOLÉ TURA, J. "Democracia y eficacia en las Cortes españolas de la transición", Parlamento y Democracia. Cit., págs. 93-108. PORRAS NADALES, A. J. Representación y Democracia avanzada. Edit. Centro de Estudios Constitucionales. Madrid 1994. RAMÍREZ JIMÉNEZ, M. "Parlamento y Opinión Pública", Anuario Jurídico de la Rioja. n. 1 1995. RAMÓN MONTERO, J. "Parlamento y opinión pública: las percepciones y los niveles de apoyo de las Cortes Generales", Revista del Centro de Estudios Constitucionales. n. ${ }^{\circ}$. Enero-abril 1989.

3 PUNSET BLANCO, R. Estudios parlamentarios. CEPC. Madrid 2001. Pág. 9 y ss.

4 Vid. CAZORLA PIETRO, L. M. "Problemas de la organización y el funcionamiento de los parlamentos actuales". El Parlamento y sus transformaciones actuales. GARRORENA MORALES, A., (Coord.) Tecnos 1990. págs. 339 y ss. También, del mismo autor, en El Congreso de los Diputados (Su significado actual) Aranzadi. Madrid 1999 
Este parlamentarismo racionalizado que refuerza al Ejecutivo ha llevado a más de uno a decir que el Parlamento está en crisis, y con ello las funciones parlamentarias han perdido su relevancia. Desde mi punto de vista no es así. Pese a la fortaleza del Poder Ejecutivo, el Parlamento sigue siendo determinante en la legitimación democrática del sistema, en la conformación de muchas posiciones políticas e, incluso, en construir y fortalecer liderazgos regenerando la clase política 5 .

El Parlamento no es la institución central de la vida política, no tanto porque el Gobierno se haya arrogado o "apropiado" de sus poderes, sino muy al contrario, porque es la Constitución la que confiere al Ejecutivo la dirección política interior y exterior en su artículo 97, lo que hace que sea éste quién tenga preeminencia en la determinación de la actividad que se desarrolla en las Cámaras, al menos en el ámbito legislativo.

El Parlamento ocupa la posición que la Constitución le ha conferido. Es la Constitución la que niega que esté en crisis cuando le otorga la legitimación de otros órganos, función legislativa y la de control político del Gobierno. Y es la Constitución la que implícitamente descarta que sea en exclusividad el órgano central del sistema cuando confiere la dirección política al Gobierno. Por ello, creo que es más útil y eficiente fijarse en las correcciones necesarias para que se cumpla el equilibrio de poderes que establece la Carta Magna, mejorando sus funciones institucionales y estableciendo un entramado orgánico y un sistema de normas adecuado para cumplir las misiones que le ha encomendado la Constitución.

En este trabajo pretendo reflexionar sobre los procedimientos de control parlamentario, por lo tanto, me situaré en el marco del derecho parlamentario y los instrumentos técnico-jurídicos necesarios para hacer más efectiva esa función constitucional.

La acotación del trabajo no me puede hacer olvidar que en la función de control es imprescindible la participación de los medios de comunicación, que se encargan de proyectar la acción política parlamentaria en la sociedad generando opinión. Más aún, medios de comunicación y actividad parlamentaria ac-

5 CAZORLA PRIETO cuando intenta dar una solución a posición en la que se encuentra hoy día el Congreso de los Diputados señala que el principio de la separación de los poderes en lo que atañe a la relación del Congreso de los Diputados con el Gobierno, aunque reflejado jurídico-formalmente de distintos modos en nuestro ordenamiento jurídico, queda en la realidad empañado y puede quedar hecho añicos por la superposición de las consecuencias del sistema de partidos y el brazo largo de la mayoría gobernante instalada tanto en el Gobierno como en la Cámara. Esta situación que no es democrática ni funcionalmente deseable y que desde luego conduce al arrinconamiento político del Congreso de los Diputados, no puede ser atajada con las viejas herramientas conceptuales e ideológicas del principio de la separación de poderes tradicionalmente entendido. Por el contrario, debe ser combatida poniendo en relieve y fomentando hasta el extremo que la preservación de un ámbito de autonomía funcional del Congreso de los Diputados en los términos que se defiende en estas líneas forma parte del espíritu democrático, sustrato básico de nuestra convivencia; en otras palabras, que tal autonomía funcional constituye una derivación muy importante del sacrosanto postulado democrático del respeto de las minorías por las mayorias. Ibidem. pág. 38. 
túan tan de común acuerdo que al igual que el trabajo parlamentario se refleja en los medios muchos asuntos que tienen su origen en la prensa acaban en los debates parlamentarios de control político. Desde luego todo esto no es nada nuevo, incluso podríamos decir que ha sido siempre así. Lo que sucede es que cada día se agudiza mucho más. Si analizamos con cierto detenimiento cómo organizan los grupos parlamentarios de la Oposición su actividad de control, observamos que en muchos casos esa actividad es complementaria de una estrategia de desgaste y crítica que se ha articulado en la dirección de esa fuerza política y que se sustenta, sobre todo, en la presencia que sus líderes tienen en los medios de comunicación. Luego el conocimiento que el Parlamento tiene de esos asuntos no es más que un "enganche", un recurso para fortalecer su mensaje y su posición política.

Como decía, esto es una obviedad, que todo el mundo conoce pero que muchas veces se olvida a la hora de analizar los procedimientos de control parlamentario. El control parlamentario debe estar organizado por normas que hagan efectiva la necesaria racionalización del trabajo de las Cámaras con la función política que tienen encomendadas. Pero para que esas normas que diseñan los procedimientos de control no sean un fracaso no se ha de perder de vista cómo funciona realmente el control: en gran parte fuera del parlamento y siendo éste en muchas ocasiones tan sólo una "caja de resonancia" de lo que se publica en los medios periodísticos.

\section{LA FUNCIÓN DE CONTROL POLÍTICO}

Sobre la importancia que tiene la función de control en la vida parlamentaria y, por extensión, en nuestro sistema parlamentario no hace falta que me extienda mucho. Basta con que cite a la doctrina más autorizada que desde hace ya muchos años mantiene algo que es una realidad evidente: la función de control ha sustituido a la legislativa en cuanto a la relevancia de los asuntos parlamentarios ${ }^{6}$.

También son bien conocidos los problemas conceptuales que presenta la idea de control ${ }^{7}$. Aunque soy consciente de la interpretación lata del control y cómo ese control sin responsabilidad, o con responsabilidad diferida (al momento de la emisión del voto por los ciudadanos), se extiende a toda los procedimientos parlamentarios, aquí me ocuparé de traer algunas propuestas para mejorar el control político en los procedimientos que según el Reglamento de la

6 Vid. GARCÍA MORILLO, J. "El Parlamento en la era global”. Cuadernos de Derecho Público. n. ${ }^{\circ} 1.1997$, págs. 81 y ss. MOLAS, I. PITARCH, I. Las Cortes Generales en el Sistema parlamentario de Gobierno, opus cit. págs. 19 y ss. MARTÍNEZ ELIPE, L. Tratado de Derecho Parlamentario. Fiscalización Política del Gobierno. V I. Aranzadi. Madrid 2000. págs. 197 y ss.

7 Vid. GARCÍA MORILLO, J. El control parlamentario del Gobierno en el ordenamiento español. Congreso de los Diputados. Monografías. Madrid 1985. págs. 41 y ss. ARAGÓN REYES, M. Constitución y control del poder, op. cit. 154 y ss. MARTÍNEZ ELIPE, L. Tratado de Derecho Parlamentario, op. cit. pág. 99 y ss. 
Cámara están dirigidos a esa función. Está claro: preguntas, interpelaciones, comisiones de investigación, proposiciones no de ley, comunicaciones y planes remitidos por el Gobierno, cuestión de confianza y moción de censura ${ }^{8}$.

Las "recetas" no son nuevas, pero sí bastante claras. Para mejorar el control político en dichos procedimientos hay que cumplir tres requisitos: primero, la posibilidad de que las iniciativas que se debatan sean de la mayor actualidad. Es decir, acercar el debate de control a los problemas que se plantean en la sociedad en cada momento. Segundo, el seguimiento por parte de los medios de comunicación de esos debates. Tercero, reforzar las iniciativas de control de los grupos de oposición. Como ya señalé, las preguntas, interpelaciones y mociones de los diputados de los grupos que sustentan al Gobierno poco aportan a la función de control. Muy al contrario, ayudan a oscurecerlo o, lo que es peor, a hacer oposición de la "oposición".

Los cambios en esta línea, sin duda que no van a suponer ninguna "revolución" de la función de control político, pero creo que puede mejorar la comunicación entre el Parlamento y la calle. Para empezar, vamos a conseguir más sintonía entre el "parlamento institución" y el "parlamento de papel". En nuestro sistema es más que frecuente que el debate político en los medios de comunicación y el debate de cada miércoles en el Congreso de los Diputados queden muy alejados 9 . Seguro que si se consigue esto habrá mucho debate "inducido" por los medios, pero también hay más posibilidad de que la actividad parlamentaria abra debates mediáticos ${ }^{10}$.

En segundo lugar, esos debates de control ante todo serán de carácter político y, por lo tanto, la oposición podrá presentar sus propuestas y sus críticas al Gobierno, pero la mayoría, y el Gobierno mismo, también tendrán oportunidad de defender sus posiciones y sus propuestas políticas. Es decir, que el debate de control no tiene porque verse tan sólo como un espacio donde la oposición "ataca" y la mayoría gubernamental se "defiende". Ha habido, y creo que puede haber muchas oportunidades dónde esa mayoría también puede "sacar los colores" a otros grupos, más si han sido Gobierno en otros momentos.

Un trabajo de derecho parlamentario, como es éste, no puede entrar en cuestiones de carácter sociológico o político, pero sí debe analizar e intentar aportar la soluciones posibles para que los procedimientos parlamentarios mediante los cuales se despliegan esos instrumentos de control inspección o con-

8 Esa tesis amplísima de concepto de control a expuso RUBIO LLORENTE, F. "El control parlamentarios". En la Revista Española de Habla Hispana. n. ${ }^{\circ}$. 1985. Frente a esta tesis está la de aquellos que entiende que instrumentos de control son tan sólo aquellos que unen responsabilidad. Vid. SANTAOLALLA LÓPEZ, F. El Parlamento y sus instrumentos de información. Edersa. Madrid 1982.

9 En la VIII Legislatura con la práctica que ha creado el Presidente Zapatero de venir todos los miércoles a responder tres preguntas este problema se ha corregido mucho. Los medios de comunicación y en especial la televisión dan buena cuenta de esa sesión de control y en particular del debate entre el Presidente del Gobierno y el lider de la oposición.

10 Vid. JIMÉNEZ DE PARGA, M. La ilusión política. ¿Hay que reinventar la democracia en España? Alianza Editorial. Madrid 1993. págs. 103 y ss. GARCÍA MORILlO, J. El Parlamento.... Op. cit. págs. 85 y ss. 
trol sanción de la actividad gubernamental se hagan en las mejores condiciones para los fines de acercamiento del Parlamento a la sociedad y sus problemas. Veamos lo que ha sucedido en estos años y las posibilidades de mejoras que se pueden deducir.

\section{PREGUNTAS PARLAMENTARIAS EN PLENO}

La tramitación de las preguntas en pleno ha sufrido una notable evolución en los veinticuatro años de vigencia del Reglamento del Congreso de los Diputados. Los cambios en estos años han ido dirigidos a facilitar que se puedan hacer preguntas que se aproximen lo más posible a cuestiones de actualidad política. Creo que también habría que reflexionar sobre los criterios de asignación de los diputados que preguntan.

El reglamento de 1982 establece que una vez que las preguntas han sido sometidas al control de admisión y calificación por la Mesa de la Cámara y publicadas en Boletín Oficial de las Cortes Generales están en disposición de incorporarse al orden del día. Como es sabido su elaboración corresponde al Presidente de acuerdo con la Junta de Portavoces (art. 67.1 RC). Pues bien, para la elaboración del orden del día del Pleno, el Presidente, de acuerdo con la Junta de Portavoces, señalará las preguntas a incluir y el criterio de distribución entre Diputados de cada Grupo Parlamentario (188.2 RC).

Del enunciado in fine del art. 188.1 del RC cabría entender que el plazo máximo para su inclusión en el orden del día es de una semana, y el mínimo de dos días. Sin embargo, para Santaolalla la "correcta interpretación de esta norma debe hacerse teniendo en cuenta el inciso final del artículo 188.4 del RC, que prescribe que las pregunta presentadas y no incluidas en el orden del dia, y la incluidas no tramitadas, deberán ser reiteradas, si se desea su mantenimiento para la sesión plenaria siguiente. Así, pues, la antelación máxima de una semana se ve drásticamente desmentida por este otro precepto (...) pues se admite la reiteración de las preguntas si se desea su mantenimiento para la sesión plenaria siguiente, ${ }^{11}$.

De las previsiones del 188.1 RC la conclusión que podemos sacar, en cuanto a los plazos para incluir las preguntas en el orden del día, es que frente a los que inicialmente pueda pensarse, priman criterios de ordenación de la actividad parlamentaria, sobre los criterios de actualidad de los temas a tratar.

Este criterio ha sido suavizado por la Resolución de Presidencia de 19 de junio de 1996. El apartado quinto de esta Resolución señala que "para la confección del orden del día de las Sesiones Plenarias sólo serán tenidas en cuenta aquellas preguntas que obren en poder del Registro del Congreso de los Diputados a las veinte horas del jueves anterior al comienzo de la Sesión Plenaria en que deban ser tramitadas.

11 SANTAOLALla LÓPEZ, F. Derecho... Op. cit., págs., 402-403. 
Un paso más de suavización da la Sección III, según la cual los Grupos parlamentarios podrán sustituir cualquiera de las preguntas formuladas por los Diputados miembros del mismo e incluidas en el orden del día del Pleno de acuerdo con el procedimiento ordinario (...) por otras relativas a los acuerdos adoptados por el Consejo de Ministros, siempre que cumplan ciertos requisitos: Presentar la solicitud antes de las veinte horas del viernes en que el Consejo de Ministro haya tenido lugar; que se especifique la pregunta sustituida y el texto de la nueva pregunta y el diputado que ha de formular la nueva pregunta (art. 7. a) b) c)).

Finalmente la Resolución de 1996, establece también la posibilidad de incorporar preguntas de especial actualidad. La Sección IV, en el artículo noveno prevé que los Grupos parlamentarios podrán solicitar hasta las doce horas del lunes de cada semana en que haya sesión plenaria la sustitución de las preguntas de algunos de los Diputados incluidas en el orden del día. Para la sustitución en estos términos de preguntas se deben dar ciertos requisitos:

- Especificar claramente la nueva pregunta y la que es sustituida, y siempre que la nueva pregunta haga referencia a hechos o circunstancias de especial actualidad o urgencia que no hayan podido registrarse por el procedimiento ordinario.

- La sustitución debe ser remitida inmediatamente al Gobierno.

- Un vez que la Mesa ha comprobado que se cumplen los requisitos la Junta de Portavoces en la reunión previa a la sesión plenaria acuerda por unanimidad y previa conformidad del Gobierno la sustitución solicitada.

La inmediación entre la presentación de la pregunta y su debate en pleno se ha acercado mucho más en el tiempo mediante Acuerdos de la Junta de Portavoces que se han convertido en uso parlamentario. En la actualidad por esta vía se ven preguntas presentadas en el Registro General del Congreso antes de las 14 horas del día anterior al del inicio de la sesión plenaria en que deban ser tramitadas. Incluso mucho más. En el supuesto de que alguna pregunta que un Grupo Parlamentario quiere incluir en el orden del día y está fuera de plazo o no ha sido admitida a trámite por la Mesa o la Presidencia, podrá incorporarse si tiene la unanimidad de la Junta de Portavoces.

Como se puede ver la tendencia es aceptar la formulación de preguntas de la forma más inmediata posible al Pleno en el que se van a discutir. Se podría decir que nuestro sistema se parece en esta cuestión cada vez más al modelo question time británico, eso sí, sin el grado de "sorpresa" e inmediación que tiene el sistema inglés.

Otro asunto importante es el de los titulares de las preguntas que se van a incluir en el orden del día. La regulación reglamentaria prima las pregunta de los grupos mayoritarios. De la lectura del art 188.2 del RC y el artículo Sexto de la RPr. de 19 de junio de 1996, se entiende que existen dos criterios a tener en cuenta a la hora de incluir y ordenar las preguntas: el de proporcionalidad en- 
tre Grupos Parlamentarios, por el que se determinan el número de preguntas que cada uno de ellos incluye en ese orden del día y el de prioridad para aquellos diputados que menos preguntas hubieran formulado durante ese período de sesiones. El primer criterio debe jugar para conocer el número total de pregunta a contestar por el Pleno, el segundo debe jugar para situarlas en el orden del día (primero la de los diputados que menos preguntas han efectuado). La conclusión final es que los dos criterios favorecen a los grupos mayoritarios. El primero porque les concede incluir más preguntas. El segundo porque al tener más parlamentarios puede repartir las preguntas entre los que menos hayan intervenido preguntando en ese período de sesiones ${ }^{12}$.

Quizás aquí también deberíamos hacer una reflexión sobre si es conveniente que el criterio para la presentación de preguntas sea igual en el grupo del partido del Gobierno que en el resto. Parece bastante evidente que las preguntas de los diputados del grupo del partido del Gobierno más que una finalidad de control pretenden ensalzar la acción gubernamental cuestión que aunque pueda ser importante rompe con la finalidad de la sección de control. Por lo tanto, sería conveniente que dicho grupo que por ser mayoritario y de acuerdo con los criterios de reparto tendría el mayor número de preguntas tuvieran que tener cierta limitación. Por ejemplo, en la VIII Legislatura se ha sentado como práctica parlamentaria que el grupo mayoritario no debe hacer más de la cuarta parte de las preguntas orales de cada sesión plenaria.

La ordenación del debate es responsabilidad del Presidente (32.1 RC). Hasta la VIII Legislatura dicha ordenación se refería tan sólo al establecimiento de los tiempos y el aseguramiento de que se cumplen los usos de cortesía parlamentaria y el resto de criterios para el buen funcionamiento de la Sesión. El artículo cuarto de la RPr. de 19 de junio de 1996 señala que se dedicarán cinco minutos a cada pregunta que se repartirán por igual al Diputado que formule la pregunta y el miembro del Gobierno encargado de responderla. El Presidente Marín ha incorporado una nueva, y desde mi punto de vista brillante practica, consistente en que las preguntas a formular en cada sesión se ordenan con el criterio de orden protocolario de cada uno de los miembros del Gobierno que la debe contestar, con lo que se consigue que las que se efectúan al Presidente y a los Vicepresidentes vayan las primeras y con ello se aumente el interés por la sesión de control.

12 Los Acuerdos de la Junta de Portavoces que se están aplicando establece: En el supuesto de que se presenten más de 24 preguntas, y después de asignar una pregunta por cada uno de los Grupos Parlamentarios a los que pertenezcan los Diputados preguntantes, tienen prioridad para sus tramitación las formuladas por los Diputados de los grupos que en el correspondiente periodo de sesiones no bubiesen consumido el cupo resultante de asignar una por cada diez Diputados o fracción; en caso de que la proporción sea la misma, la prioridad corresponde al Grupo con mayor número de miembros, si la situación de igualdad se produjese entre el Grupo Parlamentario Mixto y otro grupo tienen preferencia las preguntadas de los Diputados que hayan formulado menor número de ellas, salvo que el Grupo manifieste otro criterio de prioridad. 


\section{LAS INTERPELACIONES PARLAMENTARIAS}

El procedimiento de formulación y sustanciación de las interpelaciones no ha sufrido cambios tan importantes como veíamos en las preguntas. Tenemos un trámite que ha permanecido más estable en el tiempo. Sin embargo, eso no quiere decir que no se puedan hacer aportaciones que mejoren este instrumento de control.

Las interpelaciones, una vez superado el trámite de admisión y calificación, se mandan publicar, a los efectos de cumplir el plazo señalado en el artículo 182 del RC, para poder ser incorporadas al orden del día del Pleno.

La inclusión de las interpelaciones en el orden del día del Pleno corresponde al Presidente de la Cámara de acuerdo con la Junta de Portavoces (art. 67.1 del RC).

El criterio general para su incorporación al orden del día es el siguiente. El apartado primero del art. 182 del RC señala que las interpelaciones estarán en condiciones de ser incluidas en el orden del día transcurridos quince días desde su publicación. Esto supone que no es criterio predominante, para el art. 182, la rapidez en plantearse a discusión para que no decaiga su "oportunidad política" quizás, por ello, se dictó la Resolución de Presidencia de 17 de diciembre de 1983, que posibilita la inclusión de interpelaciones como iniciativas parlamentarias por razones de urgencia.

Las reglas que establece esa Resolución para la tramitación y el debate de interpelaciones por un procedimiento de urgencia ${ }^{13}$ son las siguientes:

- Se han de formular entre el martes y el jueves de la semana anterior a aquélla en la que se solicite su debate. Fuera de este plazo no se incluirán interpelaciones en el pleno siguiente salvo acuerdo unánime de la Junta de Portavoces.

- Se calificarán por el Presidente de la Cámara. Si éste entiende que no cumplen los requisitos debe dar cuenta a la Mesa, que adoptará la resolución oportuna.

- Si cumple los requisitos de los arts. 180 y 181 se dará cuenta inmediata al Gobierno y a los parlamentarios de su admisión a trámite.

- En las sesiones plenarias no reservadas a asuntos determinados podrán incluirse hasta tres interpelaciones de carácter urgente inmediatamente después de las preguntas orales. En ningún caso más de una del mismo Grupo Parlamentario, salvo interpelaciones aplazadas

- Tienen preferencia las interpelaciones de los Grupos Parlamentarios a la de los Diputados, así como las suscritas por grupos que todavía no hubiesen hecho uso de sus derecho a formular interpelaciones a los que si lo han hecho.

13 Resolución de la Presidencia para el desarrollo de los artículos 180 a 184, en relación con el artículo 64.4 del Reglamento. BOCG - Congreso de los Diputados-, núm. 1 de la nueva Serie E, de 17 de septiembre de 1983 . 
- Las mociones a que pudieran dar lugar se verán la próxima semana y ocuparán el lugar de una interpelación.

Como ha señalado Astarloa la rapidez con que se tramitan las interpelaciones con esta Resolución ha convertido a este instrumento de control parlamentario en uno de los más eficaces. "Preferibles a la solicitud de comparecencia porque su inclusión en el orden del día no requiere la intervención de ningún órgano de la Cámara ni depende, en consecuencia, de la mayoría...", preferible a las preguntas "...en la medida en que es posible mayor debate $y$ profundidad, e incluso preferible a las proposiciones no de ley y resoluciones "...puesto que las mociones consecuencia de interpelaciones pueden presentarse $y$ debatirse inmediatamente, sin que tampoco dependa su inclusión en el orden del día de otra voluntad que no sea la del propio autor de la interpelación y la moción ${ }^{14}$.

La doctrina y la práctica parlamentaria están de acuerdo en que las interpelaciones son un "potente" instrumento de control. Que se sustancien mediante un debate con el responsable del gobierno de la materia de que se trate y que conlleven la aprobación o rechazo de una moción en la semana siguiente, suponen integrar dos elementos esenciales de la actividad parlamentaria: contraposición de criterios entre Oposición y Gobierno y pronunciamiento del Pleno que actúa como forma de manifestar la función de indirizo de la Cámara.

En cuanto a la ordenación del debate. Primero intervendrá el autor de la interpelación y contestará el Gobierno. El interpelante podrá replicar. La primera intervención no podrá exceder los doce minutos y la réplica cinco.

Como señalaba las interpelaciones pueden dar lugar a una Moción que también se ve sometida a un control de admisión por parte de la Mesa. Se han de presentar el día siguiente al de la sustanciación de la interpelación en el Pleno. Una vez admitida la moción a trámite se debe incluir en el orden del día de la siguiente sesión plenaria. Si se presenta una Moción fuera de este plazo requerirá para su tramitación la unanimidad de la Junta de Portavoces. La inclusión en el orden del día abre el plazo para la presentación de enmiendas que se alargará hasta seis horas antes de iniciarse el debate.

El debate parlamentario de las Mociones transcurre con su presentación por el grupo proponente, por un tiempo máximo de 7 minutos; defensa de las enmiendas por orden de presentación, por un tiempo de 5 minutos; y fijación de posición de los restantes grupos también por un tiempo de 5 minutos.

Como se puede ver la Moción constituye el resultado jurídico del acto de control desarrollado mediante la interpelación ${ }^{15}$. Ciertamente, como ha señala-

14 ASTARLOA HUARTE-MENDICOA, I. Voz Interpelaciones Parlamentarias, en la Enciclopedia Jurídica Civitas, pág. 3679.

15 El Reglamento del Congreso de los Diputados señala que tanto el debate como la votación de estas Mociones tendrán lugar conforme a lo establecido para la Proposiciones no de ley (art.184.3). 
do García Morillo, la distinción entre la influencia que produce la pregunta y la moción causa de una interpelación es que en esta última concurre una declaración formal de la Cámara ${ }^{16}$. En definitiva, como ya señalé, las preguntas son instrumento de control "en el parlamento" y las mociones consecuencia de interpelación son un instrumento de control "del parlamento".

Este potente instrumento de control se podría reforzar mucho más si se llegan a establecer la interpelaciones al Presidente del Gobierno". En los trabajos que se están realizando en el Congreso de los Diputados para la reforma de su Reglamento se ha planteado esta posibilidad que sin duda daría mucha más fuerza e interés político al procedimiento. Evidentemente, tendría que ser estableciendo ciertas condiciones que hagan posible que la participación del Presiente en estas sesiones no choquen con otras ocupaciones que tiene que desarrollar. Para ello, quizás se debería establecer un límite de interpelaciones por grupo y periodo de sesiones, así como unos criterios específicos para la ordenación del debate.

\section{LAS COMISIONES DE INVESTIGACIÓN. FUNCIONAMIENTO Y MEJORAS QUE SE DESPRENDEN DE LA PRÁCTICA DE LOS ÚLTIMOS AÑOS}

Que la finalidad de las Comisiones de investigación es eminentemente fiscalizadora y de control político se deduce con toda claridad de las previsiones constitucionales y la práctica parlamentaria ${ }^{17}$. No obstante esta cuestión, principialista tiene mejor comprensión una vez visto el procedimiento que siguen los órganos parlamentarios.

La actividad parlamentaria en materia inspección viene determinada por la regulación constitucional. El art. 76 de la Constitución reconoce al Congreso de los Diputados, al Senado y a ambas Cámaras actuando conjuntamente, la posi-

16 Ibidem, pág. 176.

17 Mantiene que estamos ante un instrumento de control político: GARCÍA MORILLO, J. $E l$ control parlamentario... Op. cit, págs. 176-180; en su trabajo "El control en los tiempos del cólera". Ponencia presentada al Congreso Italo-Español de Derecho Constitucional (Toledo, 1995): La modernización de la Estructura Parlamentaria; también, en la obra conjunta, MONTERO GIBERT, J. R. GARCÍA MORILLO, J. El control parlamentario. Tecnos. 1984, pág. 55. También, MONTERO GIBERT, J. R. "Las relaciones entre el Gobierno y las Cortes Generales: notas sobre el control parlamentario y la responsabilidad política en la Constitución española", El Gobierno en la Constitución española y en los Estatutos de Autonomía. Barcelona, 1985. págs 205-219. VIRGALA FOURURIA, E. "Las comisiones y ponencias (con especial referencia al Reglamento del Parlamento Vasco)", en la obra colectiva Parlamento y Derecho. Parlamento vasco. Vitoria. 1991. págs 293-303. C A A M A ÑO DOMÍNGUEZ, F. "Comisiones Parlamentarias de Investigación vs. Poder Judicial: paralelismo o convergencia (apuntes para su debate), Anuario de Derecho Constitucional y Parlamentario. 1994, n. ${ }^{\circ}$ 6. Mantienen que estamos ante un instrumento de información: SANTAOLALLA LÓPEZ, F. "El Parlamento...", opus, cit., pág. 247. También en "Derecho parlamentario...” Op. cit, págs. 415 y ss. LUCAS MURILLO DE LA CUEVA, P. "Las Comisiones de Investigación de las Cortes". Revista de la Facultad de Derecho de la Universidad Complutense, n. ${ }^{\circ} 10$. págs. 149 y ss. 
bilidad de crear comisiones de investigación sobre cualquier asunto de interés público ${ }^{18}$. Investigación que tiene como finalidad fundamental deducir la responsabilidad política del investigado, y por lo que el propio precepto constitucional señala que sus actuaciones no son vinculantes para los Tribunales ni han de afectar a las resoluciones judiciales ${ }^{19}$. Por supuesto, esto no excluye que si se desprenden responsabilidades penales se remitan al Ministerio Fiscal para el ejercicio de las acciones oportunas.

Una última cuestión, con la que el propio texto constitucional caracteriza a estas comisiones, es la obligatoriedad de comparecer a requerimiento de la Cámara —art. $76.2 \mathrm{CE}-20$.

Teniendo en cuenta las condiciones constitucionalmente establecidas en cuanto a la constitución y desarrollo del trabajo de las comisiones de investigación, pasamos, a continuación, a ocuparnos de los trámites que preceptúan los Reglamentos de las Cámaras.

La constitución de toda comisión de investigación viene determinada por la resolución del Pleno de la Cámara que ha decidido su puesta en funcionamiento, y ha de transcurrir de conformidad con los arts. 52 y 59 del Reglamento del Congreso o del Senado respectivamente.

18 La expresión "interés público" plantea problemas de delimitación. De la experiencia parlamentaria acumulada hasta la fecha, se puede concluir que interés público se ha equiparado a todo aquello que pueda interesar a la opinión pública; aunque no es menos cierto, que sobre todo se ha incidido en aquellos asuntos de los cuales se desprende la presunción de que en la actuación del Gobierno, o de algún órgano de la Administración, han existido o existen actuaciones irregulares que se han de imputar al Ejecutivo. En ésta línea el profesor VIRGALA FOURURIA, E. Las Comisiones y Ponencias...., op. cit., pág. 294.

19 Que quede claramente diferenciada la finalidad política de la Comisión de Investigación respecto del trabajo jurisdiccional que puedan estar llevando a cabo los Tribunales preocupó especialmente en la Comisión del 11M hasta el punto de que en su Dictamen se haga la siguiente recomendación. "debe recalcarse también la necesidad de regular el desarrollo de una Comisión de Investigación cuando sobre esos mismos bechos se ha abierto, en el ámbito judicial, un proceso penal. Sin perjuicio de la posición que pueda mantenerse sobre la conveniencia o no de constituir Comisiones de Investigación cuando existe ya un proceso penal abierto, lo cierto es que si la misma se crea, deben regularse especialmente las relaciones de colaboración y mutua información entre la investigación parlamentaria y la judicial, deslindándose bien los ámbitos que corresponden a cada una de ellas. Debe recalcarse, una vez más, que la naturaleza primordialmente política de las Comisiones de Investigación nos permiten afirmar que las misma no son un tribunal. No son órganos jurisdiccionales. Están integradas por Grupos parlamentarios y determinados aspecto o competencias que en ocasiones se pretenden que las mismas conozcan, es preferible que se atiendan a través de las garantias jurisdiccionales inberentes a un proceso penal. Dictamen de la Comisión de Investigación sobre el 11 de Marzo de 2004 y de los votos particulares incorporados al mismo. Aprobado por el Pleno del Congreso de los Diputados en su Sesión de 30 de junio de 2005. BOCG. Congreso de los Diputados. VIII Legislatura. Serie D. Núm. 242, 14 de julio de 2005. Pág. 10.

20 Para conocer las condiciones de las comparencias, procedimiento y sanciones por no asistir se ha de estar a la Ley Orgánica 5/1984, de 24 de mayo, de comparecencias ante las Comisiones de Investigación del Congreso y del Senado o de ambas Cámaras. Para el requerimiento de documentos e información que estén a disposición de la Administración Tributaria se tiene que tener en cuenta el Decreto-Ley 5/1994, de 29 de abril, por el que se regula la obligación de comunicación de determinados datos a requerimiento de las Comisiones Parlamentarias de Investigación. 
El Presidente de la Cámara, en el transcurso de la primera sesión que ésta celebre, tras comprobar que existe el "quórum" de presencia necesario -art. 78.1 RC-, declarará formalmente constituida la comisión. A continuación, la Comisión ha de elegir los miembros de su Mesa, que de acuerdo con la regulación reglamentaria tendría que contar con un Presidente, dos Vicepresidente y dos Secretarios —arts. 41 RC y 53.2 del RS—, sin embargo, en los últimos tiempos está siendo práctica común que el número de miembros que componen la Mesa quede a disposición de la propia Comisión ${ }^{21}$.

Elaboración del Plan de trabajo. Constituida la Comisión, la primera actividad a desarrollar es la elaboración de su plan de trabajo. Dicho plan, que de acuerdo con los artículos 52.2 RC y 60.1 RS, es obligatorio para toda comisión que se constituya, tiene como finalidad recoger el contenido, la forma, tiempo y lugar de la investigación a realizar ${ }^{22}$. Se ha de elaborar a partir de las propuestas que hagan todos sus miembros sin más límites que su adecuación a los objetivos principales de la resolución del Pleno de la Cámara por la que se acuerda crear la comisión ${ }^{23}$.

En algunos momentos se plantearon dudas sobre el órgano al que le $\mathrm{co}^{-}$ rresponde "aprobar" el Plan de trabajo". Es cierto, como ha señalado el Dicta-

21 Aunque de acuerdo con los Reglamentos, las Mesas de las Comisiones están compuestas de cinco miembros, esta norma ha sido interpretada de forma flexible, dejándose a disposición de la propia Comisión la decisión del número de miembros que han de constituirla. Existen Comisiones Permanentes que su Mesa sólo tiene tres miembros, es el caso de la Comisión del Estatuto del Diputado; y existe el caso de Comisiones de Investigación y Estudio que se han constituido con la elección solamente de un Presidente, haciendo las veces de Secretario el Letrado de la Cámara designado para asesorarla. "Comisión Roldan", "Comisión Banesto" y "Comisión sobre financiación de los partidos políticos y su endeudamiento". En la Comisión del $11 \mathrm{M}$ se constituyó la Mesa con tres miembros, el Presidente y dos Vicepresidentes. Sesión de Constitución de la Comisión de Investigación del 11 M celebrada el 27 de mayo de 2004. Diario de Sesiones del Congreso de los Diputados. Año 2004 VIII Legislatura, núm. 1.

22 En cuanto al contenido del Plan de trabajo parece que debe coincidir con los objetivos y fines para los que se creó la Comisión, y que quedaron plasmados en el acuerdo de constitución aprobado por el Pleno de la Cámara.

En cuanto al lugar, tiempo y forma de realización de su actividad, lo normal es que lo determine el Acuerdo de creación del Pleno, de no ser así, tendremos que estar al Plan de trabajo. Para el Senado la cuestión está más clara que para el Congreso de los Diputados, al requerirle expresamente que se determinen las actuaciones y plazos (art. 60.1 RS); si embargo, la peculiaridad de la Comisión —no permanente- y la misión encomendada - investigar un asunto concreto- hace que debamos inferir como parte del Plan de trabajo el tiempo y la forma de realización, también para las constituidas en el Congreso.

23 Por supuesto, el Plan de trabajo será aprobado sin perjuicio de posibles revisiones ulteriores; de no ser así se convertiría, más que en un medio para facilitar la labor de la Comisión, en un "corset, impropio para una actividad inspectiva donde es fundamental tener la posibilidad de ampliar las demandas de información cuando las exigencias de la investigación lo requiera. $v$.gr. es la inclusión en su sesión octava de la Comisión sobre financiación de los partidos políticos y su endeudamiento, de las propuestas del Grupo Socialista y el Grupo Popular para que se estudiase e investigase, en su caso, la posible financiación, entre los años 1982 y 1990, del Partido Comunista de España por parte del Partido Comunista de la Unión Soviética. Propuesta que fue aceptada e incorporada al Plan de trabajo. Diario de Sesiones del Congreso de los Diputados. Comisiones, núm. 350, de 1994 . 
men de los servicios jurídicos del Congreso de los Diputados a la Comisión de investigación sobre incompatibilidades y tráfico de influencias ${ }^{24}$, que "aprobar" no se puede equiparar a "elaborar", que es lo que los preceptos reglamentarios reconocen a la Comisión; por tanto, de dicho término no se puede deducir la competencia de la Comisión para aprobar el Plan de trabajo. Si a esto añadimos que el art. 31.1.1 del RC reconoce a la Mesa de la Cámara la función de "... adoptar cuantas decisiones y medidas requieran la organización del trabajo y el régimen y gobierno interiores de la Cámara, podría concluirse que esa función es competencia exclusivamente de la Mesa de Cámara.

Sin embargo, la solución por la que se decanta el Dictamen de los servicios jurídicos del Congreso, con apoyo en el precedente de la Comisión de investigación sobre catástrofes aéreas, es que del silencio del art. 52 del RC se debe deducir, como regla general, la competencia de la Comisión para aprobar su Plan de trabajo, "...siempre que las actuaciones previstas (...) pertenezcan todas ellas a los tipos de actuaciones que legal o reglamentariamente puede desarrollar la Comisión y que se proyecte realizar con arreglo a las previsiones legales y reglamentarias respectivas o sin que exista previsión legal o reglamentaria que prohíba o impida su realización "25; y excepcionalmente deberán ser aprobadas por la Mesa de la Cámara, si sus actuaciones requieren la adopción de "decisiones y medidas (para)...la organización del trabajo" ${ }^{26}$.

Por lo tanto, y esta sería la conclusión, en tanto que el Plan de trabajo es el instrumento principal para organizar la actividad de la Comisión, ha de ser aprobado por acuerdo de la misma, y remitido a la Mesa de la Cámara para su conocimiento $^{27}$. Los diferentes Grupos Parlamentarios representados podrán hacer propuestas, que serán base para elaborar un texto de síntesis, que a su vez, se ha de votar y contar con la mayoría de los votos de los asistentes para su aprobación ${ }^{28}$.

La primera medida que ha de tomar la Comisión, tras la aprobación del Plan de trabajo, y de conformidad con lo allí estipulado, es el requerimiento de la

24 Dictamen de los servicios jurídicos del Congreso de los Diputados emitido a requerimiento de dicha Comisión, publicado en la Revista de la Cortes Generales, núm. 14, de 1988.

25 Ibidem, pág. 132.

26 Ibidem, pág. 131.

27 El Reglamento del Senado exige a la Comisión, además, que periódicamente informe a la Mesa de la Cámara sobre el cumplimiento del Plan de trabajo (art. 60.1 RS).

28 Los "contratiempos" que sufrió la elaboración del Plan de trabajo de la Comisión de investigación y estudio de la financiación de los partidos políticos y su endeudamiento, hace que en su Sesión tercera se hagan unas propuestas de Resolución, ante las cuales parece que el Presidente quedaba encargado de elaborar un texto síntesis, y, sin embargo, no es hasta la Sesión quinta en la que se aprueba el Plan de trabajo. Diario de Sesiones del Congreso de los Diputados, Comisiones. Núm. 238, de 1994, la Sesión tercera y Núm. 304, de 1994. La Comisión sobre el 11 M declaró, en aplicación del artículo 64.4 del RC, secretas las Sesiones 2, 3 y 4 en las que se aprobó el Plan de Trabajo. Cuestión que es más que discutible desde una práctica parlamentaria de aplicación con carácter general del principio de publicidad de los actos parlamentarios. Muchos más si tenemos en cuenta que no se está revelando nada que pueda atentar contra derechos de terceros o la seguridad del Estado y, por el contrario, se está estableciendo cuestiones de procedimiento que pueden tener interés público. 
documentación y las comparecencia de personas para asesorar o informar. Dicho requerimiento se lleva a cabo conforme a las normas generales que para comparecencia y requerimiento de documentación recogen los Reglamentos de las Cámaras - art. 44.1 y 2 del RC y 66 del RS-De acuerdo con dichos preceptos, por conducto del Presidente de la Cámara se podrá solicitar: a) la información y documentación que precisen del Gobierno y de las Administraciones Públicas ${ }^{29}$, b) la presencia de miembros del Gobierno para que informen sobre asuntos relacionados con cuestiones de su departamento, c) la presencia de autoridades y funcionarios públicos para el mismo fin, d) la presencia de otras personas competentes en la materia que se investigue. La posibilidad de que se requiera la presencia de cualquier otra persona o documentación de tipo fiscal es lo que caracteriza a estas Comisiones, que podrán hacerlo de acuerdo con el art. 53.2 del RC y los arts. 1 y 2 de la LO 5/1985, de 24 de mayo y Real Decreto-Ley 5/1994, de 29 de abril, según los cuales el requerimiento de documentación o presencia de personas - se ha de formular mediante citación fehaciente de la Presidencia de la Cámara respectiva o del Presidente del Congreso, en el caso de las Comisiones Mixtas de Investigación del Congreso y del Senado.

En cuanto a la citación deberá recoger:

— La fecha del acuerdo en virtud del cual se le requiere y la Comisión de Investigación ante la que debe comparecer.

- El nombre y los apellidos del requerido y las señas de su domicilio.

- El lugar, el día y la hora en que haya de comparecer el requerido, con apercibimiento de las responsabilidades en que pudiera incurrir en caso de desobediencia.

- El tema sobre el que deba versar el testimonio.

- La referencia expresa a los derechos reconocidos en la Ley al requeri$\mathrm{do}^{30}$.

Otros requisitos que debe cumplimentar la notificación son: que debe hacerse con quince días de antelación respecto a la fecha en la que se haya de ce-

29 Para el requerimiento al Gobierno o las Administraciones Públicas de datos, informes o documentos que obren en su poder se ha de seguir el procedimiento establecido en el art. 7.2 de RC, según el cual "La solicitud se dirigirá, en todo caso, por conducto de la Presidencia del Congreso y la Administración requerida deberá facilitar la documentación solicitada o manifestar al Presidente del Congreso, en el plazo no superior a treinta dias y para sus más conveniente traslado al solicitante, las razones fundadas en Derecho que lo impiden.

30 De acuerdo con el art. 52.2. b). La notificación al ciudadano o requerido tendrá que ser "...advertido de sus derechos y obligaciones y podrá comparecer acompañado de la persona que designe para asistirlon. Habría que señalar que la regulación de este apartado del art. 52 del RC ha venido a imponer una pequeña modificación con respecto a lo que la LO 5/1985, de 24 de mayo, en lo relativo al acompañante del compareciente. De acuerdo con el art. 3.1 de la Ley Orgánica, para que el compareciente se acompañe de alguna persona debe contarse con la conformidad del Presidente; según el precepto reglamentario, como se puede observar, dicha conformidad no es necesaria. 
lebrar la comparecencia, salvo cuando, por concurrir circunstancias de urgente necesidad, se haga con un plazo menor, que en ningún caso será inferior a tres días (art. 52.2.a del RC) ${ }^{31}$; si el requerimiento es a persona jurídica, se dirigirá a las personas que ostenten su representación legal (art. 2.3 de la LO 5/1984, de 24 de mayo); y, finalmente, en el caso de que el requerido se a funcionario público se debe enviar copia de la citación a su superior jerárquico, a los efectos de conocimiento (art. 2.4 de la misma ley).

Recopilada toda la información da comienzo la fase de estudio y la toma de "declaración" de las personas requeridas ${ }^{32}$. Es el momento clave para que aparezca el conflicto entre los principios de funcionamiento de la Cámara, y los derechos de las personas llamadas a declarar o los intereses de las entidades a las que se le requiere documentación. Por ello, el estudio de dicha documentación, y la toma de "declaración" a las personas la deberá realizar la Comisión de conformidad con las previsiones que, para salvaguardar "...el respeto a la intimidad y el honor de la personas, el secreto profesional, la cláusula de conciencia..." haya señalado la Mesa de la Cámara a la Comisión (art. 1.2 de la LO $5 / 1985$, de 24 de mayo) ${ }^{33}$.

Sobre el declarante recae la obligación legal de informar de hechos personales o de terceros que conozca. Sin embargo, esta obligación no supondrá la pérdida de los derechos antes citados, como tampoco supone la pérdida de los derechos a no declarar contra sí mismo y a no confesarse culpable de imputaciones delictivas que se le puedan hacer ${ }^{34}$.

31 Artículo redactado conforme al apartado $2 .^{\circ}$ del art. 2 de la LO 5/1984, de 24 de mayo, de comparecencias ante las Comisiones de Investigación del Congreso y del Senado.

32 De acuerdo con el art. 502.1 del CP "Los que, habiendo sido requeridos enfoma legal y bajo apercibimiento, dejaren de comparecer ante una Comisión de investigación de las Cortes Generales o de una Asamblea Legislativa de Comunidad Autónoma, serán castigados como reos del delito de desobediencia. Si el reo fuera autoridad o funcionario público, se le impondrá además la pena de suspensión de empleo o cargo público por tiempo de seis meses a dos años". Sigue señalando este artículo que "El que convocado ante un Comisión parlamentaria de investigación faltare a la verdad en su testimonio, será castigado con la pena de prisión de seis meses a un año o multa de seis a doce meses" (art. $502.3 \mathrm{CP}$ ).

33 Como se puede observar de lo dicho, la Mesa de la Cámara se convierte, sin duda alguna, en el órgano parlamentario garante de estos derechos y libertades en el ámbito parlamentario. Por supuesto esto no quiere decir que los afectados no pudieran, hipotéticamente, recurrir ante el Tribunal Constitucional si entendiese que se han violado sus derechos. Se abriría la puerta del recurso de amparo contra las decisiones o actos sin valor de ley emanados de las Cortes o de cualquiera de sus órganos — arts. 161.1.b. de la CE y 42 de la LOTC-.

34 A los derechos con que cuenta el llamado a declarar habría que sumar, como señala la profesora González Ayala, que las Comisiones de Investigación no cuentan con algunas facultades propias de la autoridad judicial: no pueden ordenar la detención de quien se niegue voluntariamente a comparecer, no pueden efectuar registros domiciliarios para descubrir pruebas, no puede intervenir la correspondencia o comunicaciones de los afectados, etc... En definitiva, las Comisiones de Investigación podrán hacer uso de las atribuciones que la LO 5/1985, de 24 de mayo, les reconoce para hacer que los requeridos comparezcan, pero sólo y exclusivamente como y según lo establece la Ley. González Ayala M. D. Las Comisiones de Investigación. Ejercicio de Titularidad, ejemplar mecanografiado consultado por deferencia de la autora, págs. 83-84. 
El trabajo de la Comisión concluye con la elaboración de un dictamen, mediante el cual se formalizan en un documento escrito las conclusiones a las que se ha llegado tras el proceso de inspección. Por ello, a la sesión encargada del debate y aprobación del dictamen se deben llevar todas las conclusiones parciales, que del estudio y conocimiento de la documentación aportada y comparecencia recibidas, se hayan deducido. En el supuesto de que se haya creado alguna ponencia, se deberá presentar, debatir y aprobar su informe, que también se incorporará como un elemento más para el dictamen.

De acuerdo con el art. 45 de $\mathrm{RC}$ y las normas sobre régimen de asesoramiento a las Comisiones de Congreso de los Diputados y el Senado ${ }^{35}$, el letrado adscrito a la Comisión redactará y presentará los informes que recojan los acuerdos que la Comisión haya ido tomando.

Con toda la información recibida y las conclusiones deducidas por las ponencias, si las hubiere, la Comisión debatirá y votará cuantas propuestas de resolución se vayan planteando por los miembros. Las conclusiones finales de esa votación conformarán el dictamen de la Comisión, que conforme al inciso final del art. 45 de RC deberá redactar el letrado y que ha de recoger todos los acuerdos adoptados ${ }^{36}$.

El dictamen debe dar respuesta a las cuestiones que conformaron los fines y objetivos para los que se constituyó la Comisión ${ }^{37}$. Ésta, como más tarde veremos, es una de las razones por las que se hace imprescindible que el Pleno conozca y debata dicho dictamen. Además, debe deducir las responsabilidades políticas que se derivan de la investigación, y proponer o recomendar la toma de iniciativas concretas a la Cámara para "atajar" situaciones similares.

El dictamen se envía al Pleno de la Cámara para su conocimiento, debate y votación. Aunque a nuestro entender, este debate ha perdido parte de su importancia, puesto que la finalidad principal —deducir la responsabilidad política- se comienza a deducir en el proceso de inspección, sigue siendo un ele-

35 Acuerdo de la Mesa del Congreso de los Diputados y el Senado, de 26 de junio. Publicado en el B.O.C.G. - Congreso de los Diputados- E.199, de 25 de junio de 1989.

36 Aunque es cierto que el trabajo de los letrados queda condicionado por la incorporación de las Actas de las Sesiones, la propuesta de Dictamen que hace el grupo mayoritario, las enmiendas de otros grupos a ese documento y los votos particulares.

37 En la Comisión sobre el $11 \mathrm{M}$ se acuerda su constitución con el siguiente objeto: a) Esclarecer la verdad acerca de los hechos sucedidos los días 11 a 14 de marzo, así como los antecedentes y consecuentes que resulten coherentes con aquella finalidad; b) Esclarecer los acontecimientos anteriores y posteriores a los atentados del 11 de marzo vinculados con éstos y las actuaciones que han realizado sobre ellos los poderes del Estado. El Dictamen que aprueba el Pleno del Congreso de los Diputados en la Sesión de 30 de junio de 2005 se organiza según los siguientes puntos: -Introducción. -Primera Parte. El terrorismo internacional y la respuesta del Estado -El terrorismo como fenómeno global -La amenaza del terrorismo islamista en España antes del $11 \mathrm{M}$-El Estado ante la amenaza terrorista islamista -Segunda Parte. El 11 M y la Gestión de la crisis por el Gobierno -El $11 \mathrm{M}$, el día más trágico de la España democrática -La reacción ante las crisis de las instituciones, de los partidos políticos, de los medios de comunicación y de los ciudadanos. -El Gobierno ante la crisis -Atención a las victimas -Tercera Parte. Recomendaciones -Anexos.

Fuente. BOCG. Congreso de los Diputados. VIII Legislatura. Serie D. Núm. 242.14 de julio de 2005. 
mento esencial. Como ha señalado la profesora Elvira Perales, «...la función de las comisiones de investigación necesita ser perfeccionada, completada por un acto del Pleno de la(s) Cámara(s); serán estas quienes finalicen la actividad de las comisiones y sin esa intervención del Pleno de las Cámaras la actividad de la comisión resultaría incompleta, inacabada, carecería de su sentido últi$\mathrm{mo}^{38}$.

El efecto externo del dictamen es que se convierte en un instrumento de colaboración con la Justicia. Lo es toda la actividad investigadora, puesto que el art. 3.2 de la LO 5/1985, de 24 de mayo obliga a que toda declaración de la que se deduzcan responsabilidades criminales se remitan a la Mesa de la Cámara para que ésta, a su vez, la remita la Ministerio Fiscal. Pero dicha colaboración está siendo reforzada con el uso parlamentario de incluir en el dictamen una propuesta al Pleno para "...que de traslado al Ministerio Fiscal de la documentación con el fin de depurar cuantas responsabilidades pudieran existir...39.

La Comisión sobre el $11 \mathrm{M}$, además de las conclusiones sobre el fondo del asunto que tenía encargado, ha hecho varias recomendaciones sobre el funcionamiento de dichas comisiones que es digno de apuntar en este trabajo e, incluso serían dignas de discutir, aunque no lo haré para no extender demasiado el trabajo. Dichas recomendaciones son:

a) La mayoría parlamentaria de apoyo al Ejecutivo no tenga poder de bloqueo o de veto a la creación de una comisión de investigación. b) Los miembros de la Comisión de Investigación tengan dedicación absoluta a sus trabajos, salvo imposibilidad de los Grupos minoritarios. c) Los medios jurídicos, técnicos y administrativos de la Comisión de Investigación sean extraordinarios para evitar el colapso de la Cámara en momentos punta. d) Se reconozca la capacidad de la Comisión de establecer resoluciones y recomendaciones provisionales a lo largo de sus trabajos. e) Las conclusiones de las Comisiones de Investigación, dada su relevancia, deberian ser editadas, publicadas y distribuidas. f) Se realice una evaluación del cumplimiento de las recomendaciones por parte de las Instituciones.

\section{LAS PROPOSICIONES NO DE LEY ${ }^{40}$}

Con las proposiciones no de ley nos encontramos ante otro supuesto paradigmático de medio de control "por el parlamento"; en palabras del profesor Aragón Reyes: “...se trata de resoluciones de una Cámara mediante las cuales

38 Elvira Perales, A. Las Comisiones de Investigación en las Cortes Generales. Ejercicio de Titularidad. Ejemplar mecanografiado que ha sido consultado por atención de la autora, pág. 29.

39 Es el caso de la conclusión primera de los dictámenes de la Comisiones "caso Roldan" y "Caso Mariano Rubio".

40 En los documentos que se han utilizado en los últimos años para la reforma del Reglamento del Congreso se propone cambiar el nombre de las Proposiciones no de Ley y llamarlas Resoluciones del Congreso. 
ésta fija su postura sobre un determinado asunto" ${ }^{41}$. En las Proposiciones no de Ley, tan importante como el debate sobre la cuestión que se plantea es la aprobación de la Resolución que conlleva. Con ella, la Cámara expresa su parecer político y requiere una forma de actuar para el Gobierno.

Los legitimados para la presentación de proposiciones no de ley son los Grupos Parlamentarios - art. 193 del RC-. Las proposiciones deberán presentarse por escrito ante la Mesa del Congreso, que decidirá sobre su admisibilidad, ordenará, en su caso, su publicación y acordará su tramitación ante el Pleno o la Comisión competente, en función de la voluntad manifestada por el Grupo proponente y de la importancia del tema objeto de la proposición (194 RC).

Como decía, la presentación de la proposición no de ley lleva implícito que el Grupo Parlamentario que la presenta deba formular la correspondiente propuesta de resolución a la Cámara. La cuestión que se plantea ante la Mesa, en cuanto a la admisión, es la de si podría admitir cualquier tipo de propuesta de resolución. Si formalmente se formula la propuesta con plena adecuación a las exigencias reglamentarias; es decir, por escrito, por un sujeto legitimado y ante el órgano competente, ¿la Mesa ha de admitirla sin más control? Entendemos que no, la labor de admisión de la Mesa juega aquí un papel relevante en cuanto necesario ajuste de la propuesta a una disciplina substantiva, tanto constitucional como reglamentaria ${ }^{42}$. Por lo tanto, no se podrán admitir propuestas de resolución contrarias al ordenamiento jurídico, cuando con ellas se intente la adopción de un acuerdo que contravenga los principios o contenidos materiales de aquél. Aunque lo anteriormente dicho pueda parecer una cuestión de pura obviedad, en la práctica no lo es tanto si observamos como algunas Asambleas de Comunidades Autónomas a menudo tramitan proposiciones no de ley instando a la Cámara a manifestar su criterio respecto de asuntos ajenos a aquélla, o a requerir al Consejo de Gobierno actuaciones que transcienden el área de su gestión ${ }^{43}$.

41 Par éste autor "La Cámara expresa su voluntad como órgano y, al hacerlo, si es crítica, negativa o conminatoria respecto de una actuación gubernamental o de un proyecto o indicación de futuro para esa actuación, cabría afirmar que de esa manera ejerce el control». ARAGÓN REYES, M. "El control parlamentario....", op. cit., Pág. 31.

42 CANO BUESO sostiene que la actividad de calificación que " compete a la Mesa no es siempre la estrictamente formal atinente a constatar la regularidad del documento parlamentario en una actividad de verificación reglada. Ni siquiera la actividad puramente técnica, carente de relevancia sustancial..." "...la regulación reglamentaria de cualquier iniciativa, en lo que se refiere a sus aspectos procedimentales, no excluye que ésta se sujete a una disciplina substantiva constitucional y estatutaria cuya extralimitación determinaría un ejercicio ilegítimo de atribuciones parlamentarias que debe ser resuelto en la fase de calificación de la iniciativa. De ahí que pueda predicarse del órgano que reglamentariamente tiene encomendada esta función la facultad de resolver cuestiones previas de fondo, tomando como parámetro a tal efecto no sólo el Reglamento parlamentario sino también la Constitución." Cano Bueso, J. "Funciones y potestades de la Mesa y de la Junta de Portavoces en el derecho parlamentario de las Comunidades Autónomas" en VVAA, Parlamento y Derecho. Seminario sobre Derecho Parlamentario celebrado los días 1 a 3 de marzo de 1990. Edit. Parlamento vasco. 1991. págs. 247-248

43 Vid. ARCE JANARIZ, A. "Admisión a trámite en los procedimientos..." Op. cit. págs. 68 a 75.

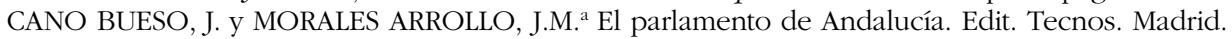
1987. Pág. 117. 
En cuanto al acto calificatorio, aquí se identifica claramente con la actividad que desempeñará la Mesa para determinar si la proposición se tramitará ante el Pleno o ante una Comisión. La Mesa optará por la remisión al Pleno o a Comisión, en función de la voluntad manifestada por el Grupo proponente y de la importancia del tema objeto de la proposición. Nos encontramos ante parámetros tan sumamente amplios y discrecionales que sólo el criterio de oportunidad e interés de la Mesa determina si estamos ante una proposición de debate en uno u otro ámbito. Finalmente, se requiere la publicación de la proposición no de ley, que supondrá abrir el plazo de presentación de enmiendas por el resto de los Grupos Parlamentarios.

En la tramitación de las proposiciones no de ley nos encontramos con actos "intermedios" o de trámite que podemos ordenar en tres grandes grupos: a) actos tendentes a la inclusión de la proposición no de ley en el orden del día. Aquellas proposiciones que se debatan en sesión plenaria se deberán incluir en el orden del día, siguiendo los criterios que para las interpelaciones establece el art. 182.2 del RC. b) actos tendentes a la incorporación al procedimiento de las enmiendas que se presenten a la proposición de ley. Conforme al art. 194.2 del RC podrán presentarse enmiendas por los Grupos Parlamentarios, desde su publicación y hasta seis horas antes de comienzo de la sesión en la que se haya de debatir. La presentación de enmiendas, vemos que se desliga del acto de inclusión en el orden del día y por lo tanto el plazo de presentación de enmiendas será más o menos amplio, dependiendo de cuando se vaya a celebrar el debate en el Pleno. c) Actos de ordenación y dirección del debate de la proposición de ley. Serán todos aquellos que tengan como sujeto activo al Presidente de la Cámara, en función de la atribución que le confiere el art. 32.1 del RC.

De acuerdo con el Reglamento del Congreso, de existir más de una proposición no de ley sobre un mismo tema, el Presidente podrá acumularlas a los efectos de su debate. Dicho debate se inicia con la intervención inicial del Grupo Parlamentario autor de la proposición (diez minutos), a la que seguirá la de los Portavoces del resto de los Grupos que hubieran presentado enmienda (diez minutos) y, concluirá con la de aquellos que no hubieran presentado enmiendas (diez minutos). De este debate debe salir la proposición a votar con la inclusión de las enmiendas que el proponente haya aceptado. En el transcurso del debate se admitirán enmiendas siempre que no se manifieste oposición por parte de ningún Grupo Parlamentario y se persiga alcanzar un acuerdo con las enmiendas presentadas.

Este tipo de resoluciones que instan al Gobierno a que actúe de una determinada manera tendrían su complemento en el plano del control si transcurrido un tiempo el Ejecutivo tuviese que presentar un informe detallado sobre el grado de cumplimiento de las propuestas de resolución aprobadas y que afecten a su actuación. Esto no es así ahora, pero sería conveniente que se introdujese en la próxima reforma. 


\section{INFORMACIÓN GUBERNAMENTAL: COMUNICACIONES, PROGRAMAS Y PLANES REMITIDOS POR EL GOBIERNO}

Nos encontramos ante diversos supuestos donde el debate sobre asuntos específicos de la política del Gobierno se efectúa a instancia del propio Gobierno. Bien, porque se remita una comunicación, un programa o un plan, solicitando su debate y el correspondiente pronunciamiento —arts 196 y 198 RC—; bien, porque se remita un informe que, por disposición constitucional o legal deba ser rendido a las Cortes Generales o al Congreso de los Diputados -201 RC - o bien, porque a iniciativa propia un miembro del Gobierno solicite comparecer ante una Comisión.

Tanto en uno en un caso como en los otros, efectuada la presentación del escrito del Gobierno, la Mesa efectuará su admisión, calificación y publicación.

El acto de admisión se ceñirá a la constatación de que nos encontramos ante un supuesto de los previstos en los artículos 196, 198 o 201 del RC. En cuanto al acto de calificación, la Mesa ha de pronunciarse sobre si la comunicación remitida por el Gobierno se ha de debatir en Pleno o en Comisión. Para ello creemos que se ha de estar a lo solicitado por el propio Gobierno y al interés que la cuestión suscite tanto en ámbito parlamentario como de la ciudadanía. En el trámite de calificación también se ha de determinar qué comisión corresponde su debate, que, por supuesto, se concreta en función de la materia. Finalmente, la Mesa ha de mandar publicar la comunicación o informe y remitirlo a la Comisión que le haya correspondido.

En la línea de lo señalado, hay que diferenciar entre: a) comunicaciones (196 RC), programas y planes remitidos por el Gobierno (198 RC), b) Sesiones informativas, que se realicen a instancia de la Cámara o petición de miembros del Gobierno.

Dentro del primer grupo, en ambos la tramitación es prácticamente idénti$\mathrm{ca}$, con la salvedad de que en el caso de encontrarnos ante un programa o plan remitido por el Gobierno, la Comisión podrá nombrar una Ponencia que estudie el programa o el plan en cuestión.

Corresponderá al Presidente de la Comisión competente, o al del Pleno en su caso, la inclusión de la comunicación o programa en el orden del día. En cuanto a la ordenación del debate, que corresponde al Presidente, se hace estableciendo ciertas condiciones - art. 196 del RC-: se determina reglamentariamente el orden de las intervenciones, (primero un miembro del Gobierno, y después un representante por cada Grupo Parlamentario); el tiempo máximo de la intervención de los representante de cada uno de los grupos, (quince minutos); la libertad al Gobierno para que organice la contestación a las cuestiones planteadas, (por separado o agrupadas en razón de la materia) y finalmente, el tiempo máximo de las réplicas que deseen efectuar los Grupos Parlamentarios, (diez minutos).

Terminado el debate, el Presidente de la Comisión, o de Pleno, abrirá un plazo de treinta minutos, durante los cuales los Grupos Parlamentarios po- 
drán presentar ante la Mesa propuestas de resolución (197 RC). Como ya vimos en su momento, dichas propuestas darán lugar a un acto de admisión por parte de la Mesa, donde su admisión o rechazo, como ya señalábamos, dependerá de si la propuesta de resolución es o no congruente con la materia objeto del debate. Importa apuntar aquí, que aunque nos encontramos ante un supuesto de calificación y admisión, estamos también ante un acto que forma parte del iter procedimental. Es un caso donde el acto calificatorio de la Mesa se ha de enmarcar dentro de los de desarrollo o impulso del procedimiento.

Las propuestas admitidas se defenderán durante un tiempo de cinco minutos como máximo y el Presidente tendrá la facultad de conceder un turno por el mismo tiempo en contra de dichas propuestas (197.2 RC). Finalmente se votará la propuesta de resolución que manifestará la opinión de la Cámara.

En cuanto a la sesiones informativas que se celebren a instancia de la Comisión correspondiente, o de algún miembro del Gobierno (202 RC), se ha de señalar que, la diferencia en cuanto a las comunicaciones, radica en que su virtualidad como mecanismo de control parlamentario se manifiesta exclusivamente en el momento en el que el miembro del Gobierno y los Grupos Parlamentarios efectúan su intervenciones, uno evacuando la información, y otros presentando preguntas y observaciones. Toda la actividad de control se agota con el debate, y por tanto, no cabe propuesta ni emisión de resolución alguna ${ }^{44}$.

Estos instrumentos que el vigente Reglamento pone en manos del Gobierno para generar un debate parlamentario sobre programas o planes de su interés podría completarse y equilibrarse si se aprueba una nueva iniciativa para reforzar el control de los grupos minoritarios sobre el Gobierno consistente en que ellos también puedan instar "debates de actualidad". Serían sesiones plenarias o de comisión donde se debatiría un asunto de actualidad que es solicitado por los Grupos Parlamentarios de acuerdo con un procedimiento específico que ayudaría a acercar a la cámara, también, los temas que interesen a los grupos de la oposición.

44 Las comparecencias de los miembros del Gobierno ante los órganos de trabajo de las Cámaras han merecido un reconocimiento especial entre los instrumentos de control para autores como Santamaría Pastor. Este autor entiende que dentro de la generalizada devaluación del resto de medios de control éste puede proporcionar un mayor volumen de información al Parlamento y, por lo tanto, una mayor posibilidad de control. Sin embargo, este instrumento de control también cuenta con problemas que restan su efectividad, según el Catedrático de la Universidad de la Autónoma éstos son dos: la ausencia de una previa información escrita por parte de la autoridad compareciente sobre los puntos sobre los que va a versar la comparecencia y, por otro, la propia estructura del debate que limita demasiado el tiempo de exposición que se concede al Gobierno y ordena las intervenciones de los Grupos parlamentarios de forma automática y mecánica. SANTAMARÍA PASTOR, JUAN ALFONSO. "La actividad de Gobierno y de la Administración como objeto de control parlamentario", en las VI Jornadas de Derecho Parlamentario. Problemas actuales del control parlamentario. Palacio del Senado, 26-27 de enero de 1995, pág. 7. 


\section{DEBATE DEL ESTADO DE LA NACIÓN}

El Debate del Estado de la Nación es un uso parlamentario que se inició a mediados de los años 80 y que se ha convertido por su solemnidad, formato y la amplitud de los temas que trata en uno de los debates más importantes de cada año.

Le confiere solemnidad que el Presidente del Gobierno aproveche este debate para hacer balance de su gestión y presente las decisiones políticas más importantes del ejercicio. También confiere solemnidad que los líderes del resto de las fuerzas políticas con representación parlamentaria intervengan para contraponer al discurso de gestión del Presidente sus criterios sobre la acción del Gobierno. No menos importante es, a los efectos de dar solemnidad, que todos los partidos y grupos se "esmeren" en la preparación de sus intervenciones y el diseño de su estrategia parlamentaria que hace que los medios de comunicación estén especialmente atentos a su desarrollo, por las declaraciones del Presidente, pero también por los discursos de contestación y réplica de los portavoces de la oposición.

El formato también contribuye a la importancia que ha adquirido. Es un procedimiento que se sustancia en dos grandes bloques: debate sobre la comunicación del Gobierno y debate de las propuestas de resolución presentadas por los Grupos Parlamentarios.

Este formato distingue entre lo que es debate-control, aunque sea sin responsabilidad, donde lo relevante es la confrontación entre la visión de la situación política que hace el Presidente y los Portavoces parlamentarios; y el debate y votación sobre las propuestas de resolución, donde lo que interesa es que la Cámara manifieste su posición política y sus recomendaciones al Gobierno.

La práctica parlamentaria en cuanto al formato del debate ha sido la siguiente. El Gobierno debe remitir a la Cámara una Comunicación en la que solicita la celebración del debate y hace un balance sobre su gestión para que identifique el objeto de lo que se ha de discutir. Recibida la Comunicación del Gobierno, la Mesa de acuerdo la Junta de Portavoces establecen los días en el que se ha de celebrar el debate (normalmente esta primera fase se desarrolla en dos días). Se inicia con la intervención del Presidente del Gobierno, que lo hace sin límite de tiempo, y una vez que concluye se suspende la sesión durante un par de horas para que los portavoces puedan "ajustar" su contestación a lo dicho por el Presidente. Se reanuda la sesión y se inicia la intervención de los grupos de mayor a menor, salvo el grupo parlamentario que sustenta al Gobierno que lo hace al final. Los portavoces tienen 30 minutos para su primera intervención y 10 en turno de réplica. Se puede conceder un turno de dúplica de 5 minutos. El Presidente puede acumular las respuestas a los Grupos Parlamentarios o contestar a cada uno de ellos.

Finalizado el debate los Grupos pueden presentar a la Mesa de la Cámara propuestas de Resolución durante un plazo que establece la Mesa y que hasta ahora no ha ido más allá de uno o dos días. También ha sido una práctica de 
este tiempo que los Grupos no puedan presentar más de un número determinado de Propuestas de Resolución (unas quince). Presentadas la Propuestas se abre el plazo de presentación de enmiendas y concluido la Junta de Portavoces ordena el debate de las Propuestas de Resolución y las enmiendas que se han aceptado por los grupos proponentes.

El debate se produce de menor a mayor de los Grupos Parlamentarios por un tiempo de unos 20 minutos y finalizado dicho debate se produce la votación de las Propuestas y sus respectivas enmiendas aceptadas.

Como señalaba al inicio, la solemnidad, agilidad y amplitud de los temas que se pueden tratar en el Debate del Estado de la Nación lo han hecho uno de los más preciados en la actividad de control de la vida parlamentaria. Sin embargo, hay un asunto que no ha quedado consolidado por la práctica parlamentaria y que desde mi punto de vista tiene especial interés para que siga teniendo la importancia que ha adquirido. Es la cuestión del mes y los días en los que se celebra. De acuerdo con la práctica actual es el Gobierno quién determina cuándo se celebra este debate, desde mi punto de vista, por el valor parlamentario que tiene y la importancia de este control no debería quedar a la disposición del Gobierno, que puede pretender "esconderlo" en momentos de menor atención de los ciudadanos, y debería ser el Reglamento de la Cámara quién estableciese una fecha, al menos aproximada (v.gr. en los meses de abril o mayo).

\section{CUESTIÓN DE CONFIANZA Y MOCIÓN DE CENSURA}

No es casualidad que los instrumentos parlamentarios y constitucionalmente más "potentes" para el control con responsabilidad presenten un escaso uso y pocos problemas en su organización y funcionamiento.

Efectivamente, la Cuestión de Confianza y la Moción de Censura son la forma más directa y efectiva para controlar la acción del Gobierno. Tanto una como la otra, de no superarse conllevan la pérdida de la confianza que el Presidente tiene para mantenerse como Jefe del Ejecutivo. Sin embargo, como todo el mundo sabe, la racionalización de nuestro parlamentarismo, junto con la potestad que el artículo 115 de la CE otorga al Presidente del Gobierno para que pueda proponer la disolución del Congreso, del Senado o las Cortes Generales, hace que la eficacia de estos instrumentos de control con sanción inmediata sean poco eficaces, más allá de escenificar un "gran debate" sobre política general.

La Cuestión de Confianza es un instrumento que pone a disposición del Presidente del Gobierno un procedimiento parlamentario para que el Congreso de los Diputados reitere su confianza sobre su programa político o una cuestión de política general ${ }^{45}$. Teniendo en cuenta el funcionamiento «férreo" de

45 Sobre el objeto de la Cuestión de Confianza, "programa político" o "cuestión de política general", se ha ocupado extensamente la doctrina para señalar que lo que pretendía el Constituyente 
los grupos parlamentarios que conforman la Cámara, la posibilidad de que el Presidente pierda una iniciativa de esta naturaleza, si se presenta, es muy escasa.

La poca eficacia de este instrumento, incluso para el Gobierno y su autoridad política", se comprueba al observar como en estos años ha sido utilizada tan sólo en dos ocasiones ${ }^{46}$. Más aún, se puede colegir que el efecto que podría producir, aunque la votación de confianza fuera ganada por el Gobierno, siempre sería negativo, puesto que estaría reflejando que la falta de acuerdo entre las fuerzas parlamentarias que sustentan al Gobierno es tan grande como para tener que requerir que formalmente en Pleno y mediante una votación se pronuncien sobre si siguen confiando en el Gobierno y su proyecto político.

La VIII Legislatura, que está siendo un buen ejemplo de Gobierno sustentado con apoyos puntuales de diversas fuerzas políticas, está demostrando que aunque alguno de los grupos que apoyaron la investidura retiren su apoyo, temporal o definitivamente, al Gobierno, éste no buscará consolidar su fuerza parlamentaria mediante una Cuestión de Confianza, sino asegurándose el voto para sus iniciativas legislativas de otros grupos que en momentos anteriores estuvieron más "remisos" "47. Como decía antes, es lógico que la "reconstrucción" de la mayoría se haga en espacios extraparlamentarios, de no ser así lo que se estaría haciendo es dando una oportunidad inmejorable a la oposición para criticar la fragilidad con la que el Gobierno tiene que sacar sus iniciativas legislativas. En definitiva, produciendo el efecto contrario a la finalidad del procedimiento, generando "desconfianza" sobre el Gobierno más que "confirmando la confianza" que necesita.

El procedimiento para la sustanciación de las cuestiones de confianza no ha cambiado en estos años, ni tan siquiera en los documentos de trabajo para la reforma del Reglamento del Congreso de los Diputados, y de acuerdo con los artículos 173 y 174 funciona del siguiente modo:

En cuanto al requisito del escrito motivado acompañado de certificación del Consejo de Ministros, para la presentación de la Cuestión de Confianza —-174

es unir este instrumento de fiducia con el acto que ha otorgado la confianza al Presidente del Gobierno, la Investidura. Por supuesto, se pretende excluir cuestiones de confianza sobre proyectos legislativos concretos. Vid. GONZÁLEZ-TREVIJANO, P.J., La Cuestión de Confianza. Mc GraW-Hall, Madrid 1996, pág. 124. FERNÁNDEZ SEGADO, F. «La Cuestión de Confianza en el marco de las relaciones Gobierno-Parlamento", de AA.VV Gobierno y Administración en la Constitución. Volumen I. Madrid 1988. Pág. 603 y ss.

46 Las dos cuestiones de confianza que se han visto en nuestra práctica parlamentaria son las siguientes: la presentada por el Presidente Suárez en 1980, que más que buscar apoyo a su política se presenta para buscar la cohesión en su partido, que tras la Moción de Censura que le había puesto el Partido Socialista habían salido muy divididos. La Cuestión de Confianza que presentó el Presidente González en 1990, para cumplir su compromiso dado cuatro meses antes al ser investido presidente de presentarla una vez que se solventarse ciertos problemas electorales que estaban pendientes desde las elecciones.

47 El caso más claro ha sido la tramitación de la reforma del Estatuto de Autonomía de Cataluña. Esquerra Republicana que ha sido aliado parlamentario del Gobierno se puso en contra del proyecto que envió la Cámara catalana y que apoyaba el grupo mayoritario, y lo que hizo el Gobierno y mayoría parlamentaria es buscarse otros aliados, en este caso Convergencia i Unió. 
$\mathrm{RC}^{48}$ - aun entendiendo que la motivación debe consistir en el cumplimiento del requerimiento del art. 112. CE - que verse sobre el programa o sobre una declaración de política general-, se plantea el problema de saber si la Mesa puede entrar a valorar tal asunto. Desde mi punto de vista, haciendo una interpretación teleológica e histórica de la voluntad del Constituyente al elaborar el art. 112 de la CE se observa que lo que pretendía era que no pudiese formularse una cuestión de confianza en relación a un proyecto legislativo concreto $^{49}$. Por lo tanto, el control de admisión y calificación de la Mesa en esta materia tiene que confirmar que lo que se persigue es la reafirmación de que el Gobierno sigue contando con el respaldo político de la Cámara, y no la aprobación de una propuesta legislativa determinada.

Una vez admitido el escrito de presentación de la Cuestión de Confianza el artículo 174.2 RC establece que el Presidente, dando cuenta a la Junta de Portavoces, convocará el Pleno del Congreso a los efectos de debatir y votar la Cuestión.

No existe una forma pormenorizada para la ordenación del debate, tan sólo se señala en el 174.3 RC que ha de seguir las normas establecidas para el debate de investidura, correspondiendo al Presidente del Gobierno y, en su caso, a los miembros del mismo, las intervenciones allí establecidas para el candidato. Por lo tanto, primero intervendrá el Presidente del Gobierno que sin límite de tiempo expondrá las razones que justifiquen el planteamiento de la cuestión de confianza y del programa o la declaración política general sobre la que se plantee. Una vez finalizada ésta, intervendrán los representantes de los grupos parlamentarios, por un tiempo no superior a treinta minutos para fijar su posición. A estas intervenciones el Presidente podrá contestar individualmente

48 Las dos cuestiones de confianza que se han visto en nuestra práctica parlamentaria son las siguientes: la presentada por el Presidente Suárez en 1980, que más que buscar apoyo a su política se presenta para buscar la cohesión en su partido, que tras la Moción de Censura que le había puesto el Partido Socialista habían salido muy divididos. La Cuestión de Confianza que presentó el Presidente González en 1990, para cumplir su compromiso dado cuatro meses antes al ser investido presidente de presentarla una vez que se solventarse ciertos problemas electorales que estaban pendientes desde las elecciones.

El caso más claro ha sido la tramitación de la reforma del Estatuto de Autonomía de Cataluña. Ezquerra Republicana que ha sido aliado parlamentario del Gobierno se puso en contra del proyecto que envió la Cámara catalana y que apoyaba el grupo mayoritario, y lo que hizo el Gobierno y mayoría parlamentaria es buscarse otros aliados, en este caso Convergencia i Unió.

Para GONZÁLEZ-TREVIJANO el requisito de que la moción se presente por escrito y con motivación origen en el primer escrito de solicitud de cuestión de confianza del Presidente Suárez en 1980, que ante el silencio de la Resolución Presidencial dictada por el Presidente del Congreso de los Diputados, de 15 de septiembre de 1980, decide acompañar a la solicitud una breve motivación de las circunstancias que le llevan a solicitar dicha cuestión de confianza. La Cuestión de Confianza, opus cit. pág. 148.

49 Con esta técnica se pretende que otorgada la confianza parlamentaria se dé la consecuencia jurídica de la aprobación en bloque de texto legislativo, ello sin posibilidad alguna de reforma parcial. Véase los Debates Parlamentarios. BOCG, n. ${ }^{\circ} 445$ de enero de 1978. Pág. 723. Voto particular de la UCD. También el DSCD, núm. 81.6 de junio de 1978, Comisión de Asuntos Constitucionales y Libertades Públicas, sesión núm. 16. Pág 2972. 
o de forma conjunta al final de todas ellas y, en todo caso, abrirá un turno de réplica de los portavoces de los grupos parlamentarios de diez minutos.

Finalizado el debate el artículo 174.4 del RC establece un período de enfriamiento de veinticuatro horas para que la Cuestión de Confianza pueda ser votada. La votación será a la hora que haya establecido el Presidente de la Cámara, votación que de acuerdo con las previsiones del artículo 85.2 ha de ser pública y por llamamiento ${ }^{50}$.

Con la Moción de Censura sucede algo parecido a la Cuestión de Confianza: que las limitaciones que establece la Constitución y el Reglamento para su presentación y las dificultades que el parlamentarismo racionalizado ofrece para que pueda prosperar hace que en pocas ocasiones se haya puesto en marcha $^{51}$.

Además, el modelo de Moción de Censura también va a condicionar el uso que de este instrumento de control se puede hacer. Como es conocido, la llamada "moción de censura constructiva" se centra en asegurar la estabilidad gubernamental impidiendo que se conformen "mayorías negativas". Oscar Alzaga argumentaba durante el debate Constitucional que la moción de censura constructiva "...logra eliminar el peligro del funcionamiento de mayorías negativas que, sin embargo, no son positivas. Es decir, la posibilidad de que se produzca el acuerdo frente a un gobierno, al efecto de derogarlo o privarlo de sus funciones, sin que esa mayoría sea capaz de generar, en términos positivos, un gobierno de recambio, 52 . Desde estos argumento se entiende que el art.113 de la CE reclame que la presentación de la moción sea respaldada al menos por la décima parte de los Diputados, y que incluya un candidato a la Presidencia del Gobierno. Estos dos requisitos, junto con la necesidad de que la moción de censura se presente de forma motivada, son condiciones que van a determinar de forma importante tanto su presentación como la forma de desarrollarse el debate parlamentario subsiguiente ${ }^{53}$.

El art. 176 del RC prevé que la Mesa de la Cámara debe comprobar que la Moción reúne los requisitos señalados en el artículo anterior: presentada por al meno la décima parte de los diputados, presentada con escrito motivado e in-

50 Ni la Constitución ni el Reglamento exigen motivación del voto. Esta ha sido una cuestión que de forma mayoritaria la doctrina ha criticado por entender que dificulta el poder conocer las razones por las que los Grupos han concedido o denegado la confianza. Por todos SANTAMARÍA PASTOR, J.A. "Las relaciones entre el Gobierno y las Cortes en el Anteproyecto de constitución", en estudios sobre el Proyecto de constitución. Madrid 1978, pág. 135 y GONZÁLEZ-TREVIJANO, P.J. La Cuestión de Confianza, opus cit., pág. 159.

51 Dos se han tramitado en todos los años de democracia. La que en los 80 presentó el PSOE al Gobierno de Suárez, cuando más que ganar la presidencia lo que se pretendía era seguir erosionando la unidad de su partido, UCD; y la presentada por AP cuando en una etapa de crisis interna cambió de Líder y pretendía mediante este sistema dar peso institucional y mediático a su nuevo Presidente, Hernández Mancha.

52 DSCD. n. ${ }^{\circ} 81$ Comisión de Asuntos Constitucionales y Libertades Públicas Sesión n. ${ }^{\circ}$ 16,6 de junio de 1978. Pág. 2973.

53 En la doctrina, por todos Vid. VÍRGALA FOURURIA, E. La Moción de Censura en la Constitución de 1978. CEC. Madrid. 1988. págs. 209 y ss. 
cluyendo un candidato a la Presidencia del Gobierno que haya aceptado la candidatura, si es así, la admitirá a trámite y dará cuenta al Presidente del Gobierno y los portavoces de los Grupos Parlamentarios. En el plazo de dos días desde la presentación de una moción de censura puedan presentarse mociones alternativas. Estas mociones deberán reunir los requisitos antes señalados.

Para el inicio del debate de la Moción la Constitución tan sólo impone que entre la presentación y su votación transcurra un plazo de cinco días. Por ello, el inicio del debate puede hacerse cuando considere el Presidente que, evidentemente, lo acordará con la Junta de Portavoces y es lógico que no sea antes de dos días desde la presentación de la primera moción de censura. El debate se inicia con la defensa de la moción por uno de los firmantes y a continuación con la intervención del candidato a Presidente del Gobierno propuesto a los efectos de que proponga su programa político de ser elegido, en ambos casos sin límite de tiempo (177.1 RC). Tras la interrupción que decrete el Presidente de la Cámara cada uno de los portavoces de los Grupos Parlamentarios podrán intervenir por un tiempo máximo de treinta minutos, también contarán con un turno de réplica de diez minutos.

En el supuesto de que se presente más de una moción de censura el Presidente, de acuerdo la Junta de Portavoces, puede decir su debate de forma conjunta. Sin embargo, la votación de todas ellas debe ser por separado y de acuerdo con el orden de presentación. Para que una moción de censura prospere será necesaria mayoría absoluta. De haberse debatido alguna más, si una ha prosperado no será necesario votar las restantes (177.3 RC).

De prosperar una moción el Presidente de la cámara debe dar cuenta de ello al Jefe del Estado y al Presidente del Gobierno. El candidato incluido en la moción se dará por investido de la confianza de la cámara para formar Gobierno (178 RC).

\section{A MODO DE CONCLUSIÓN}

Como decíamos al inicio de este trabajo, no creemos que sea posible hacer cambios espectaculares que vayan a transformar sustancialmente la función de control parlamentario. El control también está fuertemente determinado por un parlamentarismo racionalizado que desprende no pocas preferencias en los procedimientos para el grupo parlamentario mayoritario. Eso es cierto, pero sí creo que se pueden hacer mejoras al sistema. Basta comprobar las aportaciones que desde la voluntad presidencial se están haciendo en la VIII Legislatura.

Para introducir esas mejoras hay que empezar reconociendo algo que todo el mundo conoce. La racionalización del sistema tiene sentido para favorecer las iniciativas legislativas gubernamentales, incluso para catapultar sus propuestas políticas cuando se quieran hacer desde la sede parlamentaria. Ahora bien, no parece lógico que esa racionalización se lleve hasta niveles exagerados de preeminencia en los procedimientos de control. Hasta ahora, esos procedimientos de control se han organizado desde una premisa falsa. Que todos los 
grupos parlamentarios controlan por igual al Gobierno y su actividad. Y eso, como todo el mundo sabe, no es cierto. La mayoría parlamentaria y el Gobierno es la misma cosa. Luego, parece lógico que esa mayoría no tenga ninguna pretensión de controlar a su Gobierno; más al contrario, lo normal es que utilice su posición en la Cámara para favorecer la estrategia gubernamental. Por eso en la VI y VII Legislatura era tan frecuente ver como la mayoría parlamentaria utilizando las facultades que el Reglamento les ofrecía hacía "oposición a la oposición".

La racionalización no sólo se ha expresado en estos años en la preeminencia del Gobierno, también ha habido una racionalización de la organización parlamentaria. Una racionalización que ha pretendido, con buena voluntad, organizar el trabajo interno de las Cámaras de la forma más eficiente posible. La muestra más palpable es la posición central de los Grupos Parlamentarios como sujetos políticos. Toda esa organización se ha hecho estableciendo criterios de participación proporcional al número de diputados que cada grupo tiene y aplicando esos criterios de forma igual a los procedimientos de control o legislación. Precisamente aquí esta el error. Primero, los sujetos políticos en las Cámaras no son los diputados individualmente considerados hoy por hoy son los Grupos Parlamentarios, consecuentemente establecer la relevancia en los procedimientos desde criterios tan sólo numéricos es un error. Segundo, no debemos establecer una organización con los mismos criterios para los procedimientos legislativos y los de control. En la función legislativa se expresa la dirección política y por ello es lógico que Gobierno-Mayoría Parlamentaria tengan una posición preeminente; sin embargo, en la función de control se expresa la facultad de supervisión que los grupos minoritarios harán al Gobierno y sus soporte parlamentario y, no menos importante, la posibilidad de ofrecer a la ciudadanía una alternativa de gobierno, por ello, es lógico que esos grupos cuenten con ciertas ventajas.

Desde hace un cuarto de siglo tenemos el mismo Reglamento del Congreso de los Diputados. La imposibilidad para hacer reformas ha dificultado la introducción de normas en esta lógica tan coherente con la realidad del sistema. Sin embargo, como se puede comprobar en lo dicho en este artículo, las Prácticas, Usos y Resoluciones interpretativas han ido en esa dirección. Más aún, si observamos los múltiples documentos preparatorios para la reforma reglamentaria que a lo largo de los últimos diez o quince años se han hecho se puede comprobar aún con más evidencia.

Por eso creemos que si se consolida la tendencia iniciada en la regulación de las preguntas en Pleno, las mejoras en los procedimientos de las interpelaciones y sus modalidades, las nuevas proposiciones no de ley o mejoras en el funcionamiento en las comisiones de investigación daremos importantes pasos para fortalecer el control. Para ello no hace falta nada revolucionario, tan sólo voluntad política y aprobar el nuevo Reglamento. 
ABSTRACT. It is possible to enhance Parliament's political oversight powers. This paper studies some of the most common tools in our Cortes Generales for political accountability and concludes that in recent years parliamentary practice has consolidated parliamentary oversight. However, this enhancement needs to be reflected in the Standing Orders. The review of the Congress of Deputies Standing Orders is absolutely necessary to avoid Law and parliamentary practice, in this case the oversight power, taking different paths. 